\title{
Periódicos científicos brasileiros de Arquivologia: os artigos e suas autorias (1972 -2007)
}

Brazilian scientific periodicals on Archive Science: articles and their authorship (19722007)

\author{
Dr. Jayme Leiro Vilan Filho ${ }^{1}$ \\ Dra. Eliane Braga de Oliveira²
}

Resumo: descreve a evolução da produção de quatro títulos de periódicos científicos brasileiros com artigos de Arquivologia (1972-2007): Arquivo\&Administração, Arquivística.net, Acervo e Estudos Históricos. Utiliza como fonte da análise bibliométrica os dados de 400 referências bibliográficas de artigos de periódicos selecionados de uma base de dados em CDS/ISIS convertidos para MS-Excel. Apresenta tabelas e gráficos com dados absolutos e percentuais relacionados com artigos publicados por: periódico, área do conhecimento, década, origem e tipo de autoria.

Palavras-chave: periódico científico; artigo de periódico; autoria; bibliometria; Arquivologia.

Abstract: The evolution of the production of four Brazilian scientific periodical titles (Arquivo\&Administração, Arquivistica.net, Acervo, and Estudos Históricos), with articles on Archive Science, is hereby described. The data from four hundred bibliographic references to periodical articles selected from a CDS/ISIS database, turned into MS-Excel, are used as a source for bibliometric analysis. Tables and charts with absolute and percentage data related to articles, published according to periodical, knowledge area, decade, origin, and type of authorship, are presented.

Keywords: scientific journals; periodical article; authorship; bibliometrics; Archive Science.

\footnotetext{
${ }^{1}$ Doutor em Ciência da Informação. Professor Adjunto da Faculdade de Ciência da Informação da Universidade e Brasília. E-mail:jleiro@unb.br

2 Doutora em Ciência da Informação. Professora Adjunta da Faculdade de Ciência da Informação da Universidade e Brasília. E-mail: elianebo@unb.br
} 


\section{Introdução}

A literatura científica é considerada um dos três indícios de maturidade de uma área do saber e de sua institucionalização, junto com as associações ou sociedades de pesquisa, e com os cursos regulares de formação profissional e de pesquisadores (MUELLER, CAMPELLO; DIAS, 1996, p.1). Entretanto, existem diferenças substanciais entre as diversas áreas na utilização dos canais de comunicação científica, além da influência da estrutura sócio-econômica de cada país (PRICE, 1976, p.xi).

Dentre as várias formas de literatura científica, como livros, anais de congressos, teses, dissertações, patentes e até correspondência pessoal, destacamos o periódico como o mais importante em boa parte das áreas do conhecimento, incluindo as áreas de informação, ou seja, Arquivologia, Biblioteconomia, Ciência da Informação, Documentação e Museologia. Estas áreas são aqui consideradas como distintas, com características próprias e com relações interdisciplinares, como as existentes entre Biblioteconomia e Ciência da Informação, apontadas por Saracevic (1995, p. 2, 4). Todas essas áreas evoluíram compartilhando métodos e tecnologias entre si e com áreas afins - Administração, História, Comunicação, Linguística, Computação, Filosofia, Educação, Sociologia, Terminologia, entre outras - além de canais de informação, como os periódicos científicos.

No Brasil os periódicos científicos não apresentavam uma imagem homogênea até o final dos anos 90. Embora houvesse títulos com décadas de edição regular, muitos foram vítimas da síndrome dos três fascículos, enquanto muitos outros eram irregulares. Muitos periódicos científicos nacionais eram publicados de forma semi-amadora, tinham distribuição deficiente, alguns com artigos de qualidade e interesse para o país e outros com critérios de seleção irregulares. A visibilidade, o financiamento, e a distribuição eram grandes problemas dos periódicos brasileiros (MUELLER, 1999). Talvez alguns destes problemas tenham diminuído com a disseminação do periódico eletrônico no Brasil na segunda metade da década de 2000.

Em relação ao conteúdo, o periódico científico pode conter artigos, entrevistas, comunicações, recensões, entre outros, mas para Meadows $(1999$, p.166), os artigos são preferencialmente lidos e citados pelos colegas, além disso: "os artigos de periódicos sujeitos a avaliação e os livros científicos ainda são considerados como as publicações definitivas dos resultados de projetos de pesquisa."

Outros autores reforçam as afirmações de Meadows quando dizem que é o artigo de periódico científico que tem maior importância, e é também mais lido que os outros tipos de documento (TENOPIR; KING, 2001, p.16). Mueller (1999, p.2) enfatiza que "os periódicos e artigos neles publicados são usados como indicadores do desenvolvimento científico de um país ou região ou do estágio de desenvolvimento de uma área do saber", sendo também 
"indicadores de desempenho de um cientista ou instituição de pesquisa." Afirma também que a qualidade do periódico depende da qualidade dos seus artigos, além de regularidade e facilidade de acesso (idem, p.4).

Outra questão relevante é a importância relativa que os artigos têm em cada área do conhecimento, enquanto nas Ciências Exatas são mais importantes e citados, nas Ciências Sociais ocupam a segunda colocação, após os livros (MEADOWS, 1999, p.70), inclusive na Ciência da Informação (BOHN, 2003, p.14 e16).

O primeiro periódico brasileiro da área de Arquivologia, Arquivo\&Administração, surge na década de 1970 junto com outra iniciativa importante, os Congressos Brasileiros de Arquivologia, ambos criados pela Associação dos Arquivistas Brasileiros. Além destes, a década de 70 trás outras contribuições como a regulamentação da profissão de arquivista e de técnico de arquivo, e a criação dos primeiros cursos superiores de Arquivologia (FONSECA 2005). Nas décadas seguintes, nota-se uma evolução dos cursos de graduação em Arquivologia, três na década de 70, cinco nos anos 1990 e mais quatro nos anos 2000, além da produção de teses e dissertações com temática arquivística, cerca de 70 produzidas desde a década de 1990 até meados dos anos 2000 (RODRIGUES; MARQUES, 2005). Já em relação aos títulos de periódicos, a evolução não é tão grande, pois apenas um título surge em 1986 (Acervo) e mais outro em 2005 (Arquivística.net), embora tenham havido tentativas de alguns títulos que foram interrompidos, e outros de áreas afins tenham surgido e publicado artigos de Arquivologia, como Estudos Históricos.

Em relação ao conhecimento arquivístico publicado no Brasil, Jardim (1998) analisou artigos em quatorze periódicos brasileiros de Ciência da Informação, Biblioteconomia, Administração e História, no período de 1990 a 1995. Este estudo evidenciou a fragilidade da divulgação científica na área, ressaltando, inclusive a inexistência de um periódico dedicado exclusivamente à Arquivologia no período estudado ${ }^{3}$. A análise dos dados apontou, entre outros aspectos, o pequeno número de artigos publicados, a presença significativa de autores estrangeiros e a predominância de artigos procedentes do Rio de Janeiro. Cabe ainda observar que a ausência de títulos específicos, ressaltada por Jardim, implicava na dispersão da literatura de Arquivologia em periódicos de áreas correlatas. Tal dispersão foi também identificada em estudos mais recentes (VILAN FILHO; OLIVEIRA, 2008).

Outro aspecto relacionado com as autorias em uma determinada área é a autoria múltipla, ou co-autoria, que é um indicador parcial de colaboração científica (KATZ; MARTIN, 1997, p.3). Os trabalhos mais citados são escritos em colaboração e, em geral, envolvem os

\footnotetext{
${ }^{3}$ No período estudado por Jardim, o periódico Arquivo \& Administração não estava corrente.
} 
pesquisadores mais produtivos e eminentes, são mais visíveis e tem mais qualidade, com tendência geral de evolução em todas as áreas, embora de forma diferente em cada área (MEADOWS, 1999, p.109-110).

Este artigo pretende apresentar uma análise quantitativa da produção de artigos de periódicos de Arquivologia no Brasil, entre 1972 a 2007, permitindo não só comparar os resultados com estudos anteriores, como o de Jardim (1998), mas estabelecer as bases para comparações com estudos futuros. Pretende-se responder às seguintes perguntas:

1. Houve mudanças na comunicação científica da Arquivologia nos últimos 10 anos?

2. Quais os periódicos específicos da área de Arquivologia no Brasil?

3. Quais as diferenças entre os principais títulos de periódico específicos de Arquivologia?

4. Ainda persiste a presença significativa de autores estrangeiros e do Rio de Janeiro?

\section{Metodologia}

Este é um estudo bibliométrico e a bibliometria tem "um poderoso conjunto de métodos e medidas para o estudo da estrutura e do processo de comunicação acadêmica" (BORGMAN; FURNER, 2002). Além disso, as bases de dados são importantes como instrumentos de análise bibliométrica para se "traçar as tendências e o desenvolvimento da sociedade, das disciplinas científicas e das áreas de produção e consumo" (WORMELL, 1998, p.210).

Para a análise aqui desenvolvida, a fonte das informações foi a base de dados de artigos científicos de Arquivologia, Biblioteconomia, Ciência da Informação, Documentação e Museologia - ABCDM (ex-ABCID) - implementada em CDS/ISIS for Windows (WinISIS) em formato de registro compatível com o MARC21 e desenvolvida por projeto específico no Departamento de Ciência da Informação e Documentação (CID) da Universidade de Brasília (UnB), a partir de 2001. A base ABCDM contém mais de 4.700 registros de referências bibliográficas de artigos de mais de 30 títulos de periódicos científicos publicados entre 1963 e 2008 no Brasil e em Portugal, entre títulos específicos das áreas de informação e de áreas afins.

Os dados de referências bibliográficas desse estudo foram extraídos da ABCDM no WinISIS e foram inseridos no MS-Excel onde foram produzidas as tabelas e gráficos. Os registros são, em sua maior parte, de artigos científicos, embora possam existir registros de outra natureza como palestras e trabalhos de congressos, entre outros, que também são publicados nestes periódicos. Embora tenham sido publicados vários títulos de periódicos 
sobre arquivística a partir de 1972, muitos foram interrompidos ou são publicações de âmbito regional. Dentre os mais representativos estão quatro títulos incluídos na base ABCDM:

1. Arquivo \& Administração - publicado desde 1972 pela Associação dos Arquivistas Brasileiros (FONSECA, 2005, p.85-86). Divulga "estudos, atividades, experiências e reflexões acadêmicas sobre Arquivologia, tanto no âmbito nacional quanto internacional". Tem como proposta "constituir-se como espaço de difusão do saber arquivístico. Os artigos produzidos por profissionais de documentação e informação destacam-se por apresentar não só a prática arquivística, mas também as mais distintas reflexões no campo da fundamentação teórica". (AAB: CONSELHO EDITORIAL, 2007);

2. Arquivística.net - periódico eletrônico publicado desde 2005, aberto à publicação de material inserido "no escopo da Ciência da Informação e da Arquivística, em suas relações interdisciplinares com a Biblioteconomia, Museologia e Ciência da Computação, entre outros campos do conhecimento". (ARQUIVÍSTICA.NET: POLÍTICAS EDITORIAIS, 2007);

3. Acervo: Revista do Arquivo Nacional - publicado pelo Arquivo Nacional desde 1986 (FONSECA, 2005, p.86-87). Tem por objetivo contribuir para o aperfeiçoamento das técnicas arquivísticas e da metodologia de pesquisa histórica, refletindo a produção brasileira nessas duas áreas. A partir de 1993, cada número da revista passou a ser dedicado a um tema distinto. (ARQUIVO NACIONAL - PUBLICAÇÕES, 2007);

4. Estudos Históricos - publicado semestralmente desde 1988 pela Fundação Getúlio Vargas (FONSECA, 2005, p.89) é "dedicada à História do Brasil vista de uma perspectiva multidisciplinar" e "abre espaço para a publicação de trabalhos de pesquisadores da comunidade acadêmica nacional e internacional" (REVISTA ESTUDOS HISTÓRICOS, 2007).

Foram incluídos neste estudo 400 registros destas quatro publicações científicas brasileiras de Arquivologia e áreas correlatas, cobrindo os fascículos de 1972 a 2007, publicadas até setembro de 2008. As publicações serão analisadas em relação às políticas editoriais e aos temas dos artigos, visando excluir do estudo os que não são específicos de Arquivologia, antes de procederem-se análises mais detalhadas relacionadas com a produção de artigos, os índices de colaboração e a origem das autorias.

\section{Apresentação dos dados}

A primeira parte da análise visa identificar os periódicos específicos, com base na política editorial dos títulos e na temática dos artigos. O periódico Estudos Históricos foi, então, 
excluído do escopo deste estudo por ser essencialmente voltado para a publicação de textos com abordagem histórica, conforme explicitado pela própria política editorial da revista.

Em seguida, foi analisada a temática predominante dos artigos publicados nos demais periódicos, a partir do qual foram considerados específicos de Arquivologia os que alcançaram o percentual mínimo de $50 \%$ de artigos sobre a área. Assim, a revista Acervo, apesar de sua relevância como canal de comunicação do conhecimento arquivístico, não foi considerada específica da área por ter apenas $36,57 \%$ dos artigos com temática arquivística, como se observa na Tabela 1.

Tabela 1 - Artigos por periódico por área (1972-2007)

\begin{tabular}{l|cc|cc|cc}
\hline \multirow{2}{*}{ Área } & \multicolumn{2}{|c|}{ Arquivologia } & \multicolumn{2}{c|}{ Outras Áreas } & \multicolumn{2}{c}{ Totais } \\
\cline { 2 - 7 } Periódico & Nr. & $\%$ & Nr. & $\%$ & Nr. & $\%$ \\
\hline Arq.\&Adm. & 121 & $92,37 \%$ & 10 & $7,63 \%$ & 131 & $100 \%$ \\
Arq.net & 22 & $70,97 \%$ & 9 & $29,03 \%$ & 31 & $100 \%$ \\
Acervo & 79 & $36,74 \%$ & 136 & $62,96 \%$ & 215 & $100 \%$ \\
\hline \multicolumn{1}{c|}{ Totais } & 222 & & \multicolumn{2}{|c|}{155} & & 377 \\
\hline
\end{tabular}

Obs: Arquivística.net, v.3, n.2, 2007 ainda não publicado.

Fonte: dados da pesquisa.

Dentre os artigos de outras áreas publicados em Acervo, destaca-se a área de História como preponderante, podendo-se até considerá-la como uma publicação desta área, pois é tema de $50 \%$ do total de artigos deste periódico (ver Figura 1).

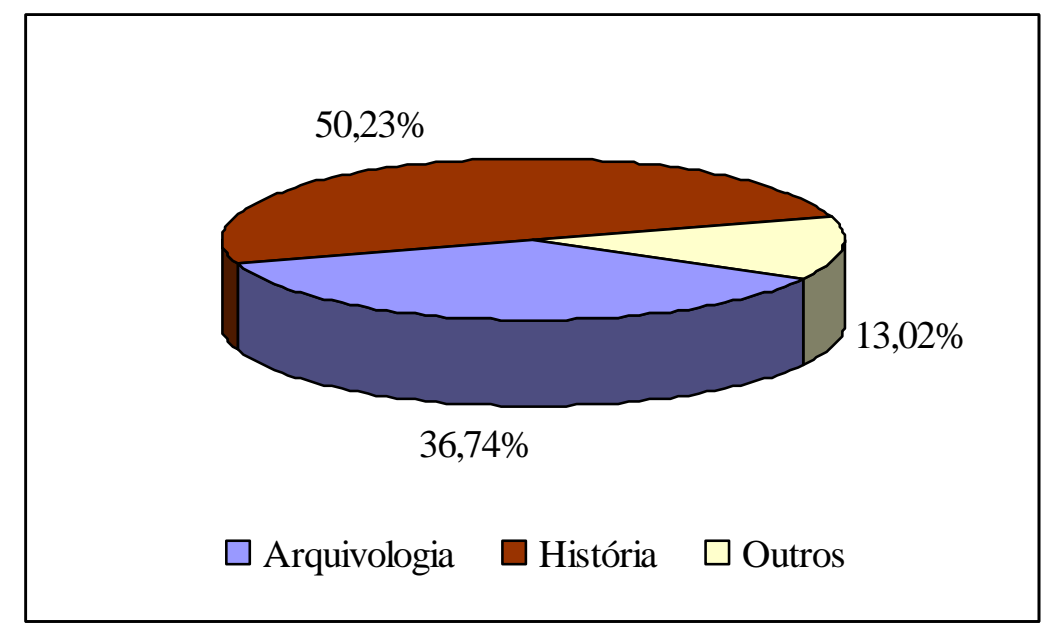

Figura 1 - Acervo: percentuais de artigos por área do conhecimento (1972-2007) Fonte: dados da pesquisa.

Na Figura 2 podemos ter uma visão geral do grau de ocorrência de artigos de Arquivologia dos periódicos Arquivo \& Administração, Arquivística.net e Acervo, destacando-se 
um percentual muito alto para Arquivo \& Administração (92,37\%) seguido de Arquivística.net (70,97\%).

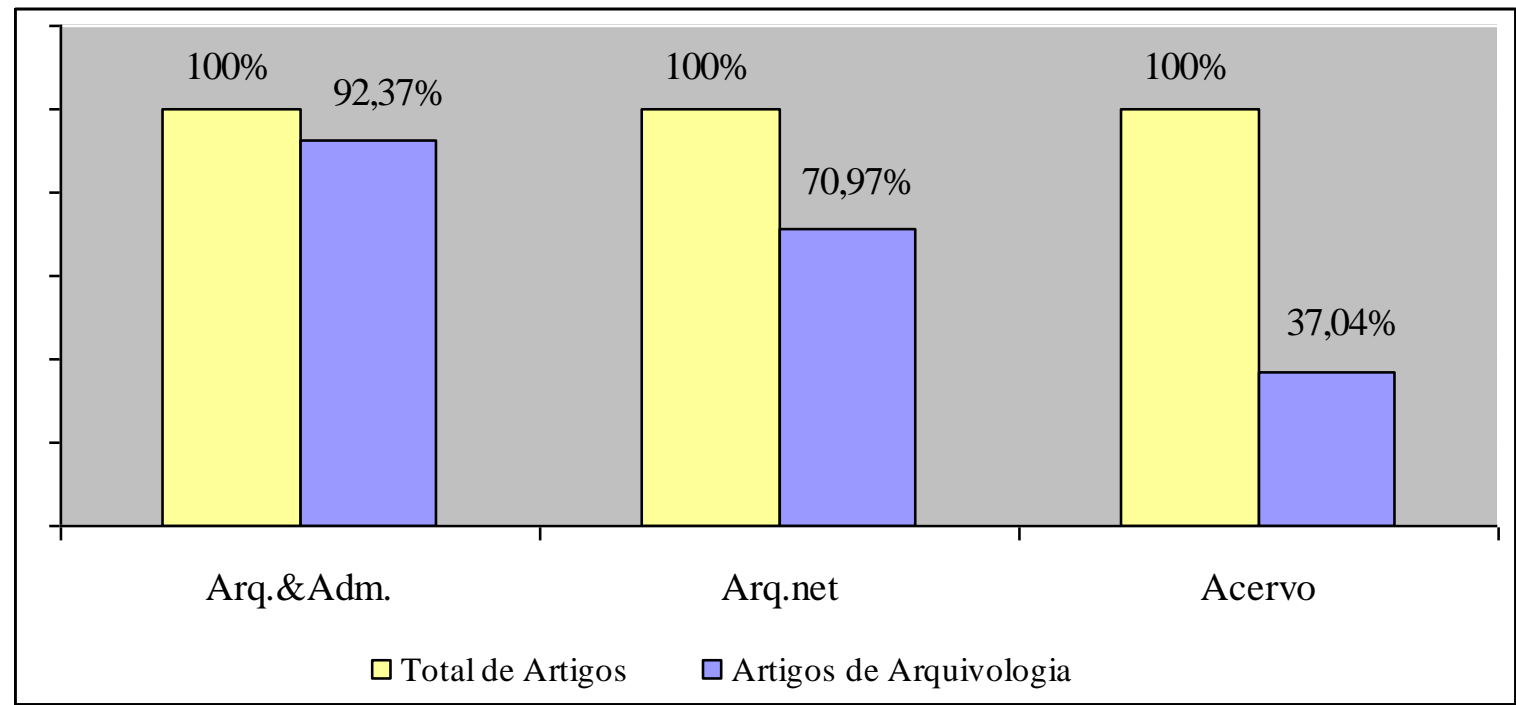

Figura 2 - Percentual de artigos de Arquivologia por periódico (1972-2007) Obs.: Arquivística.net, v.3, n.2, 2007 ainda não publicado.

Fonte: dados da pesquisa.

A partir deste ponto o estudo concentrou-se apenas nos periódicos considerados específicos: Arquivo \& Administração e Arquivística.net.

Tabela 2 - Artigos sobre Arquivologia de periódicos específicos por década (1972-2007).

\begin{tabular}{c|cc|c}
\hline DécadalPeriódico & Arq.\&Adm. & Arq.net & Totais \\
\hline 1970 & 45 & - & 45 \\
1980 & 30 & - & 30 \\
1990 & 20 & - & 20 \\
2000 & 26 & 22 & 48 \\
\hline Totais & 121 & 22 & 143 \\
\hline
\end{tabular}

Obs.: Arquivística.net, v.3, n.2, 2007 ainda não publicado.

Fonte: dados da pesquisa.

Pode-se observar na Tabela 2 que a produção de artigos dos periódicos específicos de arquivologia decresceu no decorrer das décadas de 1980 e 1990, de 45 para 20 artigos, retomando os níveis próximos da década de 70, com 48 artigos, apenas nos anos 2000. Além disso pode-se observar que durante três décadas a área dependeu de apenas um periódico específico, mesmo assim com periodicidade irregular, não sendo publicado de 1982-1985, 1987-1993, 1995-1997 e 2000-2003. Durante este período, especialmente de 1986-1989 e 1993-1999, boa parte da produção da Arquivologia foi publicada em periódicos de áreas afins como Acervo e Estudos Históricos (VILAN FILHO; OLIVEIRA, 2008). 
Quanto às autorias ${ }^{4}$ dos artigos de Arquivologia, observa-se na Tabela 3 que a maior parte é de autorias vinculadas a instituições localizadas no estado do Rio de Janeiro $(65,74 \%)$, seguidas de autorias estrangeiras (22,22\%). Observa-se ainda que a concentração de autorias do Rio de Janeiro (75\%) é bem maior no periódico Arquivo\&Administração, enquanto há uma maior distribuição da origem das autorias em Arquivística.net entre o Rio de Janeiro (25\%), o Distrito Federal e Minas Gerais (20\%), e São Paulo e Rio Grande do Sul (15\%). Em relação às autorias estrangeiras a disparidade entre os periódicos é maior ainda pois apenas no periódico Arquivo\&Administração elas foram identificadas, e com índices significativos $(27,27 \%)$.

Tabela 3 - Procedência geográfica das autorias de artigos sobre Arquivologia por periódico específico (1972-2007)

\begin{tabular}{c|cc|cc|cc}
\hline Periódico & \multicolumn{2}{|c|}{ Arq.\&Adm. } & \multicolumn{2}{|c|}{ Arq.net } & \multicolumn{2}{c}{ Totais } \\
\hline Origem Autores & Nr. & $\%$ & Nr. & $\%$ & Nr. & $\%$ \\
\hline RJ & 66 & $75,00 \%$ & 5 & $25,00 \%$ & 71 & $65,74 \%$ \\
DF & 11 & $12,50 \%$ & 4 & $20,00 \%$ & 15 & $13,89 \%$ \\
SP & 9 & $10,23 \%$ & 3 & $15,00 \%$ & 12 & $11,11 \%$ \\
MG & - & $0,00 \%$ & 4 & $20,00 \%$ & 4 & $3,70 \%$ \\
RS & - & $0,00 \%$ & 3 & $15,00 \%$ & 3 & $2,78 \%$ \\
SE & 1 & $1,14 \%$ & - & $0,00 \%$ & 1 & $0,93 \%$ \\
ES & 1 & $1,14 \%$ & - & $0,00 \%$ & 1 & $0,93 \%$ \\
PR & - & $0,00 \%$ & 1 & $5,00 \%$ & 1 & $0,93 \%$ \\
Estr. & 24 & $27,27 \%$ & - & $0,00 \%$ & 24 & $22,22 \%$ \\
ND & 9 & $10,23 \%$ & 2 & $10,00 \%$ & 11 & $10,19 \%$ \\
\hline Totais & 88 & $100 \%$ & 20 & $100 \%$ & 108 & $100 \%$ \\
\hline
\end{tabular}

Estr. - autores estrangeiros; ND - não disponível.

Obs.: Arquivística.net, v.3, n.2, 2007 ainda não publicado.

Fonte: dados da pesquisa.

Na Tabela 4 podemos observar a distribuição das origens das autorias no decorrer das décadas, com destaque para a diminuição do percentual de autorias com origem no Rio de Janeiro na década de 2000 (51,43\%), enquanto na década anterior (1990) elas representavam quase $90 \%$. Quanto às autorias do Distrito Federal, parecem estar retomando, na década de 2000, os mesmos níveis da década de 1970 (20\%), após níveis abaixo de 10\% nos anos 1980 e 1990. A década de 2000 trás também uma proporção maior de autorias de Minas Gerais (11,43\%), São Paulo e Rio Grande do Sul (8,57\%). Quanto às autorias estrangeiras, após o índice diminuir de $23,33 \%$ para $11,11 \%$, entre os anos 1970 e os anos 1980 , passa a aumentar significativamente nas décadas seguintes, chegando a $28,57 \%$ nos anos 2000 .

\footnotetext{
${ }^{4}$ O conceito de autoria, relação autor-artigo, difere do conceito de autor, indivíduo. Um mesmo autor pode ter várias autorias de artigos distintos.
} 
Tabela 4 - Origem dos autores de artigos de periódicos específicos de Arquivologia por década (1972-2007)

\begin{tabular}{c|cc|cc|cc|cc|cc}
\hline Década & \multicolumn{2}{|c|}{1970} & \multicolumn{2}{|c|}{1980} & \multicolumn{2}{|c|}{1990} & \multicolumn{2}{|c|}{2000} & \multicolumn{2}{c}{$1970-2000$} \\
\hline Origem Autores & Nr. & $\%$ & Nr. & $\%$ & Nr. & $\%$ & Nr. & $\%$ & Nr. & $\%$ \\
\hline RJ & 22 & $73,33 \%$ & 17 & $62,96 \%$ & 14 & $87,50 \%$ & 18 & $51,43 \%$ & 71 & $65,74 \%$ \\
DF & 6 & $20,00 \%$ & 2 & $7,41 \%$ & 1 & $6,25 \%$ & 6 & $17,14 \%$ & 15 & $13,89 \%$ \\
SP & 1 & $3,33 \%$ & 7 & $25,93 \%$ & 1 & $6,25 \%$ & 3 & $8,57 \%$ & 12 & $11,11 \%$ \\
MG & - & $0,00 \%$ & - & $0,00 \%$ & - & $0,00 \%$ & 4 & $11,43 \%$ & 4 & $3,70 \%$ \\
RS & - & $0,00 \%$ & - & $0,00 \%$ & - & $0,00 \%$ & 3 & $8,57 \%$ & 3 & $2,78 \%$ \\
SE & 1 & $3,33 \%$ & - & $0,00 \%$ & - & $0,00 \%$ & - & $0,00 \%$ & 1 & $0,93 \%$ \\
PR & - & $0,00 \%$ & - & $0,00 \%$ & - & $0,00 \%$ & 1 & $2,86 \%$ & 1 & $0,93 \%$ \\
ES & - & $0,00 \%$ & 1 & $3,70 \%$ & - & $0,00 \%$ & - & $0,00 \%$ & 1 & $0,93 \%$ \\
Estr. & 7 & $23,33 \%$ & 3 & $11,11 \%$ & 4 & $25,00 \%$ & 10 & $28,57 \%$ & 24 & $22,22 \%$ \\
ND & 8 & $26,67 \%$ & - & $0,00 \%$ & - & $0,00 \%$ & 3 & $8,57 \%$ & 11 & $10,19 \%$ \\
\hline Totais & 30 & $100 \%$ & 27 & $100 \%$ & 16 & $100 \%$ & 35 & $100 \%$ & 108 & $100 \%$ \\
\hline
\end{tabular}

Estr. - autores estrangeiros; ND - não disponível.

Fonte: dados da pesquisa.

Em relação à autoria múltipla, indicador parcial de colaboração entre pesquisadores, os dados da Tabela 5 indicam um crescimento substancial na década de 2000 nos periódicos específicos de Arquivologia, de cerca de 20\% nas décadas de 1980 e 1990 para 32,20\%, com comportamentos diferentes nas demais áreas de informação. Considerando todo o período de estudo, 1972 a 2007, o percentual dos periódicos da Arquivologia (22,84\%) é maior do que o índice da área de Museologia (18,07\%) e mais próximo do índice da área de Biblioteconomia e Documentação (25,96\%).

Tabela 5 - Percentuais de artigos em autoria múltipla por área, por década e por períodos decrescentes (1972-2007)

\begin{tabular}{|c|c|c|c|c|}
\hline Década\Área & $\begin{array}{c}\text { A.M. } \\
\text { Arquivol. }\end{array}$ & $\begin{array}{c}\text { A.M. } \\
\text { Bibl.\&Doc. }\end{array}$ & $\begin{array}{l}\text { A.M. } \\
\text { C.I. }\end{array}$ & $\begin{array}{l}\text { A.M. } \\
\text { Museol. }\end{array}$ \\
\hline 1970 & $14,58 \%$ & $20,22 \%$ & $12,94 \%$ & $0,00 \%$ \\
\hline 1980 & $20,59 \%$ & $23,45 \%$ & $14,58 \%$ & $15,38 \%$ \\
\hline 1990 & $19,05 \%$ & $13,46 \%$ & $66,98 \%$ & $20,90 \%$ \\
\hline 2000 & $32,20 \%$ & $47,06 \%$ & $42,94 \%$ & $18,13 \%$ \\
\hline $1972-2007$ & $22,84 \%$ & $25,96 \%$ & $31,30 \%$ & $18,07 \%$ \\
\hline 1991-2007 & $28,75 \%$ & $35,35 \%$ & $34,75 \%$ & $18,43 \%$ \\
\hline $2001-2007$ & $32,20 \%$ & $52,22 \%$ & $43,90 \%$ & $17,65 \%$ \\
\hline
\end{tabular}

A.M. - autoria múltipla, C.I - Ciência da Informação Fonte: dados da pesquisa.

Quando consideramos o índice médio de artigos em autoria múltipla (ver parte inferior da Tabela 5), os dois periódicos específicos de Arquivologia evoluíram de 22,84\% (1972-2007), para $28,75 \%$ (1991-2007) e para 32,20\% (2001-2007). Este crescimento também foi observado 
em patamares maiores nas áreas de Biblioteconomia ${ }^{5}(25,96 \%, 35,35 \%$ e 52,22\%) e Ciência da Informação $^{6}\left(31,30 \%, 34,75 \%\right.$ e 43,90\%), divergindo apenas em relação à área de Museologia ${ }^{7}$ (18,07\%, 18,43\% e 17,65\%), que mantém índices médios por volta de 18\% nos mesmos períodos. Destaque para a área de Biblioteconomia e Documentação que alcançou índice médio superior a 50\% (2001-2007).

\section{Conclusões}

Embora o estudo tenha limitações relacionadas com os freqüentes atrasos de publicação dos fascículos, a irregularidade dos periódicos e a cobertura da base $A B C D M$, que não inclui a produção de todos os periódicos regionais e de áreas afins, permite visualizar a evolução da produção de artigos científicos da área de Arquivologia no Brasil, ainda que com alguma distorção. Considerando a análise de apenas dois periódicos específicos, um irregular e outro muito recente, além da ausência de dados mais completos sobre artigos de arquivística em periódicos de áreas afins, o estudo levanta mais questionamentos do que aponta conclusões relacionadas com eventuais mudanças na comunicação científica da área, nos últimos dez anos. Alguns pontos podem ser destacados: a retomada na produção a níveis da década de 1970, a oferta de canais de comunicação mais acessíveis, em meio eletrônico, e a maior abrangência geográfica das autorias.

Existem dois periódicos específicos de Arquivologia correntes, Arquivo\&Administração e Arquivística.net, e há evidências de que a área de Arquivologia dependeu de publicações interdisciplinares, como Acervo e Estudos Históricos, para disseminar parte da sua produção científica nas décadas de 1980, 1990 e início da década de 2000.

O periódico que publicou mais artigos com temática arquivística, apesar das freqüentes interrupções, foi Arquivo\&Administração (121), seguido pelo periódico Acervo (79). Uma análise detalhada dos artigos publicados na Acervo evidencia que mais de $60 \%$ dos artigos nela publicados são de áreas correlatas e não de Arquivologia, com destaque para História ( $50 \%$ do total). Essa característica já havia sido ressaltada por Jardim (1998) e Fonseca (2005) em seus respectivos estudos e pode ser confirmada com os dados obtidos nesta pesquisa. Esse é um dado que deve ser ressaltado por tratar-se do periódico da instituição arquivística máxima do país, o Arquivo Nacional.

\footnotetext{
${ }^{5}$ Em 1.360 artigos publicados entre 1972 e 2007 nos periódicos: Revista de Biblioteconomia de Brasília, Revista da Escola de Biblioteconomia da UFMG, Cadernos de Biblioteconomia, Revista Brasileira de Biblioteconomia e Documentação, Revista ACB e Biblos.

${ }^{6}$ Em 1.460 artigos publicados entre 1972 e 2007 nos periódicos: Ciência da Informação, Transinformação, Datagramazero, Informare e Ponto de Acesso.

${ }^{7}$ Em 249 artigos publicados entre 1972 e 2007 nos periódicos: Ciência em Museus, Revista Museu, MUSAS, Anais do Museu Histórico Nacional e Revista Eletrônica Jovem Museologia.
} 
Com relação à autoria dos artigos de Arquivologia, foi possível confirmar as características já observadas por Jardim (1998). Embora o percentual de autorias do Rio de Janeiro esteja decrescendo, ainda há uma concentração que merece a reflexão da comunidade arquivística, uma vez que atualmente existem 12 cursos de Arquivologia localizados em diversas unidades da federação. É interessante ressaltar que os índices de origem geográfica das autorias são muito diferentes entre os dois periódicos específicos: Arquivo\&Administração tem uma maior concentração de artigos do Rio de Janeiro (75\%) em relação à Arquivística.net (25\%). Esse aspecto merece maior investigação, pois a disparidade cronológica entre os dois é muito grande: enquanto o primeiro tem décadas de publicação, o segundo tem apenas três anos.

Quanto às autorias estrangeiras o índice aumentou em relação às décadas anteriores chegando a $28,57 \%$ de $2000-2007$. Isso também merece um estudo específico, pois os dados tanto podem indicar que os referenciais teóricos e metodológicos da Arquivologia brasileira ainda estão no exterior, como podem refletir um desejo da comunidade científica arquivística brasileira na manutenção do intercâmbio com seus pares internacionais.

Em relação à autoria múltipla, a área de Arquivologia seguiu a tendência de crescimento da maioria das áreas de informação e alcançou índice de quase um terço dos artigos em colaboração nesta década $(32,20 \%)$, após ter permanecido no patamar próximo a $20 \%$ por duas décadas (1980-1999).

A presença dos profissionais de arquivo na pós-graduação, aparentemente, não está refletida na produção de artigos sobre Arquivologia, tanto no que diz respeito ao número de artigos publicados sobre o tema, quanto na origem geográfica dessa produção.

Os dados aqui apresentados apontam para a necessidade de pesquisas que incluam outros indicadores, tais como: a existência de periódicos especializados de âmbito regional, a incidência de artigos sobre arquivologia em periódicos específicos de outras áreas de informação, as características da prática de publicação dos profissionais da área e os pólos de produção de conhecimento arquivístico no país.

Finalmente, a fragilidade da divulgação científica, apontada por Jardim e reafirmada nesta pesquisa, somada ao processo de consolidação da área, sugere que o espaço privilegiado para a produção do conhecimento arquivístico, a academia, deve também repensar seu papel na construção de canais eficientes para a divulgação do conhecimento produzido no país, seja nas universidades ou nas instituições arquivísticas.

\section{Bibliografia}

AAB: CONSELHO EDITORIAL. Disponível em: http://www.aab.org.br/ acessado em 12/10/2007. 
ARQUIVÍSTICA.NET: POLÍTICAS EDITORIAIS. Disponível em:

http://www.arquivistica.net/ojs/policies.php\#focus acessado em 12/10/2007.

ARQUIVO NACIONAL (BRASIL): PUBLICAÇÕES. Disponível

em:http://www.arquivonacional.gov.br/cgi/cgilua.exe/sys/start.htm?sid=31 acessado em $12 / 10 / 2007$

BOHN, Maria del Carmen Rivera. Autores e autoria de periódicos brasileiros de ciência da informação. Encontros Bibli, n.16, 2. sem. 2003.

BORGMAN, Christine L.; FURNER, Jonathan. Scholarly communication and bibliometrics. Annual Review of Information Science and Technology, v.36, p. 4-59, 2002.

FONSECA, Maria Odila K. Arquivologia e Ciência da Informação. Rio de Janeiro: Editora FGV, p. 85-91, 2005.

JARDIM, J. M. A produção de conhecimento arquivístico: perspectivas internacionais e o caso brasileiro (1990-1995). Ciência da Informação, Brasília: IBICT, v.27, n.3, 1998.

KATZ, J.S.; MARTIN, B.R. What is research collaboration? Research Policy, v.26, 1997, p.1-18.

MEADOWS, A.J. A comunicação científica. Brasília: Briquet de Lemos, 1999.

MUELLER, Suzana Pinheiro Machado; CAMPELLO, Bernadete Santos; DIAS, Eduardo Wense. Disseminação da pesquisa em ciência da informação e biblioteconomia no Brasil. Ciência da Informação, v.25, n3, 1996.

MUELLER, Suzana Pinheiro Machado. O círculo vicioso que prende os periódicos nacionais. DataGramaZero, n.0, dez. 1999. Artigo 04.

PRICE, Derek J. de Solla. O desenvolvimento da ciência: análise histórica, filosófica, sociológica e econômica. Rio de Janeiro: Livros Técnicos e Científicos, 1976. 98 p. Tradução de: Little Science, Big Science.

REVISTA ESTUDOS HISTÓRICOS. Disponível em: http://www.cpdoc.fgv.br/revista/htm/re perfil.htm acessado em 12/10/2007.

RODRIGUES, Georgete M.; MARQUES, Angélica A. C. A inserção da Arquivística nos cursos de pós-graduação stricto sensu no Brasil. In: Revista Brasileira de Pós-Graduação, Brasília, v. 2, n. 3, p. 75-92, mar. 2005.

SARACEVIC, Tefko. A natureza interdisciplinar da ciência da informação. Brasília, Ciência da Informação, v.24, n.1, 1995. Acessado 04 jul. 2006 em http://www.ibict.br/cienciadainformacao/viewarticle.php?id=575\&layout=abstract.

TENOPIR, Carol; KING, Donald W. A importância do periódico para o trabalho científico. Revista de Biblioteconomia de Brasilia, v.25, n.1, p.15-26, jan./jun. 2001.

VILAN FILHO, Jayme Leiro; OLIVEIRA, Eliane Braga de. A produção de artigos nos periódicos científicos brasileiros de Arquivologia (1972-2006). Congresso Brasileiro de Arquivologia, 15. Goiânia, 2008. Anais...

WORMELL, Irene. Informetria: explorando bases de dados como instrumentos de análise. Ciência da Informação, Brasília: IBICT, v. 27, n. 2, p. 210-216, maio/ago. 1998. 